\title{
Analysis on Composition, Characteristics and Functions of Network Young Option Leaders in China
}

\author{
Beibei Kong \\ College of Agricultural, Henan University of Science and Technology, Henan Luoyang, 471000 \\ China
}

Key words: Internet age, Young opinion leader, Composition, Characteristic, Function.

\begin{abstract}
Based on the actual situation where diversified information technologies contend for development in the internet age, synchronous development of market economy and civil society injects energy for operation of modern society and also offers fundamental conditions for the emergence of young opinion leader. This paper mainly discusses the composition, characteristics and functions of network young opinion leaders in China. To be specific, the analysis is from the following aspects: exerting the function of public opinion guidance, constructing young network culture and driving good behaviors of the public through personal practice. This paper hopes the effect of network young opinion leaders in China can be fully manifested and it can make greater contributions to maintaining social harmony.
\end{abstract}

\section{Introduction}

Young opinion leaders may be deemed as "the activists" who go through interpersonal communication network and provide effective information resources for others. In China, network young opinion leaders often appear in internet platform, and they can generate certain influence among the youth group. Nowadays, the young people at the age below 30 have become the "main force" of network young opinion leaders in China. To make more people understand network young opinion leaders in China more comprehensively, this paper discusses the composition, characteristics and functions of network young opinion leaders in China.

\section{Analysis on Composition of network young opinion leaders in China}

\section{Outstanding Young People in Media Circle}

In internet age, the young people in media field have certain superiority in the aspect of becoming network young opinion leaders. This is mainly because they have an all-round understanding of various news information transfer forms and operation links. Besides, with the specialty advantage, they can deeply analyze and explore the essence of social information, understand social behaviors and psychological behaviors of the public more thoroughly. Hence, they can create social topics which can attract the public.

\section{Elites in Business Circle}

They pay great attention to social issues closely related to people's livelihood such as educational system reform, real estate market. The appearance of such network young opinion leaders is mainly because the position of wealth concept continuously improves in the development process of market economy, and wealth has become an important index to measure individual achievements. The thought and behavioral pattern of young people are profoundly influenced. 


\section{Young Recreation and Sports Starts}

The emergence of such network young opinion leaders is mainly because young idols extend their infection in practical life to network platform. With the assistance of individual characteristics and fans, they ascend to the throne of network young opinion leader. For example, the number of fans owned by Lu Han, Yao Ming and other recreation and sports stars is calculated with 100 million. On the emerging platform - internet, fans can share their experience with stars and get different spiritual feelings. Of course, young recreation and sports stars become network opinion leaders, which cannot be accomplished in an action. This is closely related to their fame offline. Han Han becomes famous, because he has published numerous youth literature periodicals. Thus, he becomes a young opinio0n leader in the aspect of public affairs field.

\section{Young Political Talents}

Such network young people take delight in concerning realistic problems in the society. With the help of new media, they convey their own ideas. They profoundly realize that internet can generate huge influence in the society. More and more young cadres with foresight apply microblog and other network media to carry out system construction, implement the system and deal with emergencies. Young politicians investigate social events in the form of real-name registration and anonymity discussion. For example, a political cadre comments "the case of maid prostitution" under the network name of "Qiu Zhen De Li Liang” in an objective and sincere way, and his opinion is affirmed by many netizens.

\section{Exploration of Characteristics of Network Young Opinion Leaders in China}

\section{Wide Sources}

In current stage, the emergence of network opinion leader phenomenon is not surprising. In the information society, young opinion leaders spread in all walks of life. After distinguishing and studying the identity of network young opinion leaders, we have found that they are not just social elites or a specific social team. Another typical feature of network young opinion leaders is timeliness in terms of gaining social information resources. Especially after an important event happens in the society, network young opinion leaders can analyze the essence of the event fast via automatic terminal with their acute insight. Besides, some network young opinion leaders get more information about an event through their interpersonal relationship.

\section{Delight in Sharing Subjective Opinions}

To discover social information resources fast, every network young opinion leader must own the quality of profound insight and subjective opinions, independent thinking spirit and strong expression desire. Network young opinion leaders take delight in sharing their opinions on a social event, and they are good at proposing suggestions or ideas on social topics. The contents they publish in network environment are rich, and their words are decent. Their quality is top-grade, and their individuality is fresh. They belong to "personality-type" figures and manifest certain personality color. Network young opinion leaders depend on network environment and convey their suggestions and ideas on a social event or topic. If they can gain the attention of network media operators, they may likely achieve multiple objectives of guiding public opinion and creating social issues.

\section{Infection of Public Behaviors in the Form of Equal Interactions}

In the old society of China, the class idea was deep-rooted so that vertical administrative control system was established. The setup of social organization and power operation link reflected stationarity. In the internet age, the effect of superior-subordinate administration system is greatly weakened $^{[1]}$. Besides, fans greatly support network young opinion leaders. The force of fans makes the influence range of network young opinion leaders on public opinion expand in the linear form. 
The ideas of network young opinion leaders present the features of uniformity, assistance and exclusiveness. Therefore, network young opinion leaders pay more attention to the quality of interactions with their fans so as to construct associated opinion leader group with strong social influence.

\section{Overview of Functions of Network Young Opinion Leaders in China}

\section{Presenting Netizens' Demand}

In Chinese traditional society, the long-term inheritance of class management idea resulted in an impassable gulf between government agency and grass-roots masses. The appeal of grass-roots masses suffered various obstacles in the submission process, and it was hard for the government agency to give ear to and perceive conditions of the people. The existence of conditionality in the communication channel made the trust of grass-roots masses in the government and their dependence on the government show the declining trend. As times goes on, social stability will be affected.

In the virtual internet environment, groups can convey their subjective will fast and conveniently via forums and websites. The birth and development of network young opinion leaders promote the will of grass-roots masses to be fully shown. This is mainly because young opinion leaders live in the information society, receive higher education and own rich cultural deposits and scientific literacy. In addition, most of network young opinion leaders grow in the folk society, which has great superiority in the aspect of capturing actual needs of grass-roots masses. Based on the cognition of national political mechanism and operation situation, they are happier to convey their appeal to the superior department from the public perspective. Then, network young opinion leaders evolve into the hub of effective communication between the superior government and grass-roots masses.

For example, the price of corns in the northeast China dropped sharply in 2016. For this situation, many corn plantation households had learned the state carried out 8-year temporary corn storage policy and enjoyed certain subsidy, but they were still astonished at the price of corns. ${ }^{[2]}$ "Can the price of corns rise?" "What is the range of price rise?" "Whether should peasants plant corns by a large margin?” All these questions were put forward by numerous grass-roots peasants. They badly needed the guidance of relevant departments and professionals. Since grass-roots masses cannot convey their actual conditions, network young opinion leaders should play a role and publish the above information on internet platform to get the answers of insiders. For instance, Li Guoxiang (a researcher of Rural Development Research Institution, Chinese Academy of Social Sciences) gave the following explanation for the question "How about the price of corns in the future?": the price of corns will not drop sharply in current stage; according to the standard quality ( $13 \% \sim 15 \%$ moisture), the price of corns is about 1.4 Yuan $/ \mathrm{kg}$; this is the rough price of international market. In the future, corn plantation area in China should reduce 25 million mu at least to reach the goals of driving the entire demand and improving supply-demand relationship. It thus can be seen that under the aid of young opinion leaders, the confusion of grass-roots masses is solved so that they can plan and adjust future plantation plans.

\section{Guiding Public Opinions}

Network young opinion leaders convey social topics in the form of planning youth discussion agenda and architecture and finally guide public opinions. ${ }^{[3]}$ Compared with traditional paper media and other mass media, the amount of information conveyed by network young opinion leaders becomes increasingly larger, and most information has been evolved into social hot issues.

For instance, for the hot topic of "low-carbon economy and low-carbon life", network young opinion leaders actively published carbon emission concept and China's statistical monitoring system for carbon dioxide release which was established during "the $12^{\text {th }}$ Five-year Plan" on network platform in order to guide more people to take active part in "green life" system. Besides, they proposed to adjust energy structure, research and develop more new and renewable energy sources, 
innovate industrial structure, increase the investment in technological industry and service industry and improve consumption mode and life style. Under the guidance of network young opinion leaders, the public profoundly cognize the threat of "high carbon" on sustainable development of China, and it is also a direct factor deriving from climate warming issue. Under the cooperation of network young opinion leaders, low carbon economy has become a global consensus. Low carbon life has become a mode of life loved by the masses and is reflected in various aspects of life, such as walking for short-distance journey, saving paper, printing and recording on both sides; turning off the power in time; using recyclable cloth bags during shopping. ${ }^{[4]}$ In one word, network young opinion leaders actively communicate the concept of "low carbon economy" and "low carbon life", which can practically optimize human ideology and improve their behavioral patterns. These are reflected in three aspects: saving electricity, saving gas and recycling.

In one word, network young opinion leaders have the functions of guiding development direction of social topics and expanding the coverage of public opinions. In this way, the forces in each field can be integrated to achieve the ultimate objective. Compared with most people following the trend, network young opinion leaders are always active on the internet platform, and they are full of enthusiasm and devotion. They carefully observe social development trend and combine their advantages to create individualized and timely topics. In the process of topic investigation and development, the cognitive framework of young opinion leaders becomes more substantial. The objective and profound reply to the questions proposed by modern young people make them affirm and pursue their ideas. Then, the direction of social event operation will not deviate. In recent years, network young opinion leaders have played a more and more significant role in terms of guiding public opinions. Thus, network young opinion leaders should always keep rigorous attitude in the aspect of selecting social topics.

\section{Constructing Youth Network Culture}

In the information age, the competition for mainstream speaking right by various countries in the world is not just reflected in military and economy. The effectiveness of soft power will stand out in the competition process. As everyone knows, one of important reflection forms for soft power is culture $^{[5]}$. As internet technology becomes popular in the world, network culture will generate profound influence on psychological state and cultural quality of social masses.

At present, internet platform can be regarded as the "plantation land" of emerging culture. The operation trend of network buzzwords and fashionable words can indirectly reflect cultural background and features of modern life. For a long time, Chinese Communist Party and government agencies pay high attention to the development of network culture, and create clean, harmonious, healthy and upward network environment for Chinese netizens with diversified means.

Based on the actual conditions of internet popularization and application as well as continuous rise of adolescent netizens, the conclusion that network environment quality is closely related to physical and psychological health of teenagers can be speculated. The governments at all levels should actively take administrative and legal means to maintain the quality of network environment. But, they are still powerless to create good network culture. Network young opinion leaders undertake the mission of cultivating and creating favorable network culture, communicating positive energy and socialist core values and creating good environment for physical and psychological health of young netizens in China.

In the process of creating network culture, network young opinion leaders always stick to the principle of abandoning the false and retaining the true as well as discarding the dross and selecting the essential and input cultural activities and cultural products which can motivate teenagers' driving force for struggling on internet platform so as to lay a foundation for achieving network spirit creation $^{[6]}$. In terms of network culture construction, the functions of network young opinion leaders are usually reflected in the following aspects: 1) develop network culture technology. To be specific, elites enhance the research on key techniques such as "firewall" and "computer password", and compress the expenses of surfing internet under the aid of broadband business; 2) create unique 
network culture brand and product with the help of network cartoon, network music and network literature; 3) actively advertise the significance of network culture construction and make netizens achieve the ideological consensus on creating civilization website and network environment through carrying out the activities of "network civilization atmosphere" and "sunshine green network project"; 4) manage network culture and embody the pertinence and effect. Network young opinion leaders in China adopt the management idea of suiting the remedy to the case to prepare a set of feasible countermeasures to manage and control vulgar network culture, and actively create novel, scientific and popular network culture so as to make vulgar and decadent network culture initiatively quit from the internet platform.

\section{Conclusions}

Based on the above contents, we know main types and characteristics of network young opinion leaders as well as the guidance and construction functions they exert on internet platform. To give full play to the role, network young opinion leaders as the future hope of the nation should establish great ideal, actively learn advanced cultural concept, know the latest national policy in time and make greater contributions to development and progress of modern society.

\section{Acknowledgments}

This paper is a specials research topic of ideological and political education of university students in Henan University of Science and Technology: Study on Cultivation and Management Mode of School Network Opinion Leaders, No. 2015SZ006

\section{References}

[1] Zhong Zhe, Gao Yuan, Network Trend of Political Participation by Contemporary Youth and the Enlightenment on Prevention and Treatment of Disordered Street Politics. China Youth Study, 2015,(11):43-49+63.

[2] Gao Tian, Study on Network Sudden Mass Disturbance under new Media Age. Shandong Social Sciences, 2015,(09):105-112.

[3] Wang Guohua, Wei Chengrui, Zhong Shengyang, Wang Yalei, Wang Ge, A Quantitative Interpretation and Characteristics Study of Microblog Opinion Leader's Network Media Power-A Perspective of Social Network Analysis. Journal of Intelligence, 2015,(07):117-124+70.

[4] Yue Jinxia, Chen Xiao, Cultivation and Guidance of Undergraduate Network Opinion Leaders. Journal of Shengli College China University of Petroleum, 2015,(02):57-60.

[5] Lan Jiayun, Yang Ziwen, The Opinion Leader's Cyber Misconduct and its Countermeasures under High-frequency Forwarding in the Micro Era. Journal of Hunan University(Social Sciences), 2015,(02):144-148.

[6] Liu Yuanzhen, Analysis on Roles and Functions of Network Opinion Leaders under New Media Environment. Journal of News Research, 2015,(02):48+87. 